\title{
Pena de morte em tempo de guerra e a incompatibilidade com a tutela dos direitos humanos
}

\author{
Death penalty in war time in Brazil and the \\ incompatibility with the protection of the human rights
}

\section{Paulo César Correa Borges* \\ Stella Mendes Costa*}

\section{Resumo}

O respeito à dignidade humana, princípio fundamental dos direitos humanos, é a base para a construção e manutenção do Estado Democrático de Direito, no qual até mesmo as sanções do jus puniendi buscam a efetivação desse Estado de caráter mais humanitário e menos supressor de direitos e garantias. A vida digna humana não só se sobrepõe a outros bens jurídicos fundamentais universalmente tutelados como norteia a aplicação de todo o ordenamento nacional, inclusive a tutela penal. Nesse contexto, a pena de morte em tempo de guerra, constitucionalmente expressa no ordenamento brasileiro (Constituição Federal de 1988) - no art. $5^{\circ}$, XLVII, a - perde suas justificativas e vai de encontro aos limites democráticos fundamentados pelo próprio Estado brasileiro. O Código Penal Militar, legislação infraconstitucional que especifica os crimes suscetíveis à pena capital, também se mostra incompatível com tais limites dos direitos humanos. Busca-se, dessa forma, compreender e revelar as fontes da incompatibilidade da pena de morte em tempo de guerra, prevista pela Constituição Federal e pela legislação infraconstitucional, diante do panorama contemporâneo de reconhecimento e tutela de direitos humanos fundamentais.

Palavras-chave: Pena de morte. Guerra. Direitos humanos. Dignidade humana.

Possui graduação em Direito pela UNESP (1990), é mestre (1998) e doutor (2003) em Direito pela UNESP - Universidade Estadual Paulista Júlio de Mesquita Filho. Realizou Pós-doutoramento na Universidade de Sevilla - Espanha (2012). São Paulo - SP - Brasil. Email: pauloborges@franca. unesp.br

* Graduada em Direito pela Universidade Estadual Paulista “Júlio de Mesquita Filho" - Unesp. Tem experiência na área de Direito Penal, Direito Constitucional e Direitos Humanos. São Paulo - SP - Brasil. Email: stella_mendesc@hotmail.com 


\section{Abstract}

Respect for human dignity, fundamental principle of human rights is the basis for the construction and maintenance of a democratic state, in which even the sanctions of the jus puniendiseek enforcement of this state of a more humane and less suppressor of rights and guarantees. Dignified human life not only override other fundamental legal rights universally protected, such as guiding the implementation of the entire national system, including the protection of criminal law. In this context, the death penalty in time of war, expressed in the Brazilian Constitution (1988), lose their justification against the limits justified by the democratic state. The Military Penal Code, that specifies the crimes susceptible to capital punishment, is also incompatible with such powers of human rights. The aim is to understand and reveal the sources of the incompatibility of the death penalty in time of war, provided by the Constitution and the brazilian legislation, on the contemporary landscape of recognition and protection of fundamental human rights.

Keywords: Death penalty. War. Human rights. Human dignity.

\section{Introdução}

O ordenamento jurídico nacional, complementado por normas internacionais, aponta para uma efetiva aproximação dos princípios fundamentais dos direitos humanos. A tutela da dignidade da pessoa humana, tendo por base o Estado Democrático de Direito, é o ponto de partida para a aplicação de qualquer norma ao caso concreto. No exercício de sopesamento de razões e contrarrazões, atividade precípua a essa aplicação, a vida digna humana prevalece diante de todos os outros bens jurídicos fundamentais.

A pena de morte, no contexto desse Estado democrático que busca a proteção jurídica dos direitos do homem, perde suas justificativas. A Constituição Federal de 1988 (CF/88) - em seu artigo 5, XLVII, a é, portanto, parcialmente coerente ao declarar a proibição da pena de morte, pois, ao defender direitos e liberdades fundamentais, não poderia aceitá-la, mesmo em caso excepcional, como em tempo de guerra. 
O Brasil não é o único país a defender a possibilidade da pena de morte como exceção em tempos de guerra. Os países ibéricos (Espanha e Portugal), de marcante influência no ordenamento brasileiro, também a adotam. O artigo 15 da Constituição Espanhola diz:

Todos tienen derecho a la vida y a la integridad física $y$ moral, sin que, en ningún caso, puedan ser sometidos a tortura ni a penas o tratos inhumanos o degradantes. Queda abolida la pena de muerte, salvo lo que puedan disponer las leyes penales militares para tiempos de guerra.

A Constituição portuguesa admitiu a pena de morte para crimes de guerra até 1976, quando a aboliu: "Art. $24^{\circ}$ [...] 2. Em caso algum haverá pena de morte".

O presente artigo se propõe a compreender tal incompatibilidade partindo da atual estruturação da dignidade humana dentro do ordenamento jurídico nacional, incluindo os tratados internacionais de direitos humanos assinados pelo Brasil. Além disso, partindo da ideia lançada por Bachof (1951) sobre a existência de normas constitucionais, inconstitucionais e da teoria proposta por Rubio (2010) a respeito da construção permanente dos direitos humanos, busca-se afirmar que a aplicação do princípio da dignidade da vida humana não pode sofrer relativizações, sob o risco de esvaziar todo o seu significado.

\section{Dignidade humana}

O pós-guerra marcou o período de reconstrução dos direitos humanos, quando não só foi revisada a ideia de soberania absoluta do Estado, mas também os direitos de cada indivíduo passaram a ser protegidos na esfera internacional. A necessidade de reconstrução surge a partir dos resultados obtidos pela aplicação do Direito Penal Intervencionista, que, ao buscar restaurar a credibilidade do sistema punitivo por meio do recrudescimento penal, levou ao fortalecimento de Estados autoritários, nos quais a pena passou a ser vista não por sua eficácia para a organização e efetivação da segurança da sociedade, 
mas como verdadeiro instrumento de terror contra a sociedade (BORGES, 2005).

A Declaração Universal de 1948, nessa conjuntura, introduziu a concepção contemporânea dos direitos humanos como universais e indivisíveis. Indivisíveis por formarem uma unidade interdependente e inter-relacionada, já que o desrespeito de um deles leva ao comprometimento dos demais; e universais por defenderem que o único requisito comum à sua aplicação é a condição de ser humano (PIOVESAN, 2010). A dignidade passa a ser o ponto principal para a efetivação dos direitos humanos.

O parágrafo $5^{\circ}$ da Declaração de Direitos Humanos de Viena, de 1993, diz: "direitos humanos são universais, interdependentes e inter-relacionados. A comunidade internacional deve tratar os direitos humanos globalmente de forma justa e equitativa, em pé de igualdade e com a mesma ênfase".

Os princípios fundamentais que integram o Direito positivo são traduzidos em verdadeiras normas-matriz, por revelarem as valorações políticas acolhidas pelo constituinte. Tais princípios representam a essência para a integração e interpretação da própria Constituição e de outras normas do ordenamento interno, de forma a garantir a coerência de todo o sistema (SILVA, 2000).

A primeira legislação a erigir a dignidade humana como um direito fundamental foi a Lei Fundamental da República Federal da Alemanha, devido ao contexto de práticas cruéis e desumanas contra os judeus durante o nazismo. Em 1988, o constituinte brasileiro, com fresca lembrança do regime militar e de seus desrespeitos à pessoa humana, inseriu esse direito fundamental como um valor supremo em nosso ordenamento.

A Constituição Federal de 1988 é a lei que fundamenta todo o Estado Democrático de Direito brasileiro. Nela, encontra-se uma integração dialética de vários elementos da vida em sociedade, como a estrutura do Estado e do poder, as garantias e os direitos fundamentais de cada um dos cidadãos. A Constituição abrange direitos individuais, 
políticos, sociais e econômicos que foram sendo construídos ao longo de toda a história.

A Declaração dos Direitos do Homem e do Cidadão, adotada pela Assembleia Constituinte francesa de 1789, conferiu aos direitos do homem um valor universal. Ela trouxe princípios como a legalidade, a liberdade, a igualdade, a democracia e a dignidade humana, fundamentais para todo Estado de Direito, os quais foram, a partir de então, desenvolvidos e aprimorados em cada ordenamento e tratado internacional.

No sistema interamericano, o Pacto de San José da Costa Rica, que entrou em vigência em 1978, é o principal instrumento regional de proteção aos direitos humanos. Piovesan (2010) destaca que a necessidade da complementação do sistema global por um sistema regional está ligada ao fato de que este garante maior autenticidade às peculiaridades e aos valores históricos do povo de uma determinada região, como forma de ampliar e fortalecer a tutela dos humanos.

Além disso, destaca que obter consenso político para a estruturação dos textos políticos e da forma de monitorar a aplicação deles é mais fácil devido a uma maior homogeneidade entre países vizinhos. É precípuo reafirmar, todavia, que os sistemas regionais não excluem o sistema global, mas complementam-no, a fim de efetivar a tutela à vida digna humana, à igualdade, à liberdade e à segurança.

Há um crescente anseio do Estado brasileiro em efetivar a tutela e a promoção dos direitos humanos, demonstrado não só pelo Programa Nacional dos Direitos Humanos (PNDH-3) de 2010, mas também pela assinatura de tratados internacionais que dão consubstancialidade jurídica aos direitos humanos, tais como o Pacto Internacional dos Direitos Civis e Políticos, a Convenção contra a Tortura e outros Tratamentos ou Penas Cruéis, Desumanos e Degradantes e, especialmente, o Pacto de San José da Costa Rica e seus protocolos adicionais.

Os tratados de direitos humanos são considerados pelo texto constitucional preceitos constitucionais equivalentes às próprias normas ali contidas, não existindo, portanto, hierarquia entre elas. Piovesan 
(2010) afirma que não só os tratados de direitos humanos têm o status de norma constitucional, por força do $\S 2$, do art. $5^{\circ}$, como também têm admissão automática em nosso ordenamento, consoante prescreve o art. $5^{\circ}, \S 1^{\circ}$ da CF/88.

Desde o julgamento do Recurso Extraordinário n466.343, em março de 2008, o Supremo Tribunal Federal passou a entender que se o tratado de direitos humanos for aprovado nos termos do art. $5^{\circ}, \S 3^{\circ}$, ou seja, caso seja aprovado pelo quórum de três quintos em cada Casa do Congresso, será norma equiparada à Emenda Constitucional, portanto, será norma formal e materialmente constitucional.

Para os demais tratados de direitos humanos, em especial aqueles ratificados anteriormente à Emenda Constitucional n 45/2004, que introduziu o parágrafo terceiro ao artigo $5^{\circ}$, ficou reconhecida a tese de supralegalidade.

Com relação ao sistema global, o Pacto Internacional dos Direitos Civis e Políticos de 1966 , em seu art. $6^{\circ}$, inciso $2^{\circ}$, permite que a pena de morte seja aplicada apenas de forma excepcional e nos casos de "crimes mais graves". Há o protocolo adicional a esse Pacto relativo especificamente à abolição da pena de morte, adotado pela Assembleia Geral da ONU em 1989, mas que entrou em vigência apenas em 1991.

O protocolo dispõe que a abolição da pena de morte não só contribui para a promoção da dignidade da pessoa humana, como também reflete o progressivo desenvolvimento dos direitos humanos. Pautado no art. $3^{\circ}$ da Declaração Universal dos Direitos Humanos, de 1948, e no art. $6^{\circ}$ do Pacto Internacional sobre os Direitos Civis e Políticos, o protocolo traz onze artigos e a única exceção aceita diz respeito aos casos de "condenação por infração penal de natureza militar de gravidade extrema cometida em tempo de guerra"1.

"Artigo 20: 1. Não é admitida qualquer reserva ao presente Protocolo, exceto a reserva formulada no momento da ratificação ou adesão prevendo a aplicação da pena de morte em tempo de guerra em virtude de condenação por infração penal de natureza militar de gravidade extrema cometida em tempo de guerra." 
Já no sistema interamericano de direitos humanos, o Pacto de San José da Costa Rica, também denominado de Convenção Americana sobre Direitos Humanos, de 1969, proíbe penas desumanas e degradantes ${ }^{2}$, como a pena de morte. É uma norma internacional que deve prevalecer no caso de conflito entre ela, a Constituição Federal e o Código Penal Militar.

O protocolo adicional ao Pacto de San José da Costa Rica, relativo à abolição da pena de morte, determina que esta, nos Estados-membros, não pode ser aplicada a nenhuma pessoa submetida a sua jurisdição. 0 protocolo, pautado no artigo $4^{\circ}$ da Convenção Americana sobre Direitos Humanos e na ideia de que toda pessoa tem o direito inalienável de respeito à vida, não havendo qualquer motivo para a suspensão desse direito, proíbe qualquer reserva ao protocolo, exceto no caso previsto no próprio documento, restrito aos delitos militares graves. Brasil e Chile, por imperativos constitucionais, consignaram essa reserva.

O protocolo afirma, ainda, que a pena de morte não só produz consequências irreparáveis que impossibilitam a correção de qualquer erro judicial como também elimina qualquer possibilidade de reabilitação do condenado.

O Supremo Tribunal Federal entende que mesmo sendo os pactos e seus respectivos protocolos normas formalmente infraconstitucionais, elas devem prevalecer por serem as mais favoráveis à pessoa humana e sua dignidade.

2 "Artigo $4^{\circ}$ - Direito à vida:1. Toda pessoa tem o direito de que se respeite sua vida. Esse direito deve ser protegido pela lei e, em geral, desde o momento da concepção. Ninguém pode ser privado da vida arbitrariamente.2. Nos países que não houverem abolido a pena de morte, esta só poderá ser imposta pelos delitos mais graves, em cumprimento de sentença final de tribunal competente e em conformidade com a lei que estabeleça tal pena, promulgada antes de haver o delito sido cometido. Tampouco se estenderá sua aplicação a delitos aos quais não se aplique atualmente.3. Não se pode restabelecer a pena de morte nos Estados que a hajam abolido.4. Em nenhum caso pode a pena de morte ser aplicada a delitos políticos, nem a delitos comuns conexos com delitos políticos.5. Não se deve impor a pena de morte a pessoa que, no momento da perpetração do delito, for menor de dezoito anos, ou maior de setenta, nem aplicá-la a mulher em estado de gravidez.6. Toda pessoa condenada à morte tem direito a solicitar anistia, indulto ou comutação da pena, os quais podem ser concedidos em todos os casos. Não se pode executar a pena de morte enquanto o pedido estiver pendente de decisão ante a autoridade competente". 


\section{Direitos humanos}

Rubio (2010) parte do pressuposto de que os direitos humanos são resultado de movimentos e lutas sociais ao longo de toda a história, imprescindíveis para o início do processo de institucionalização e reconhecimento normativo de tais direitos, primeiro com debates teóricos e discussões acadêmicas, ganhando gradualmente espaço em tratados internacionais e nas legislações nacionais.

Além desse caráter jurídico positivista e formalista, Rubio (2010) defende os direitos humanos como uma estrutura mais complexa que se constrói dinamicamente a partir de práticas e ações humanas, tendo como pressuposto a aceitação e a forma como esses direitos são assimilados por cada sociedade.

A necessidade de complementação do sistema global por um sistema regional de proteção aos direitos humanos, defendida por Piovesan, vai ao encontro dessa necessidade por uma sensibilidade sociocultural.

A forma como os direitos humanos são entendidos e significados em cada espaço social serve para potencializar, ou esvaziar, as dimensões da cultura dos direitos humanos.

Essa dimensão cultural, concebida como o conjunto de práticas sociais, simbólicas, culturais e institucionais que cada pessoa exerce dentro de sua sociedade, comunidade, e mesmo no âmbito familiar, aproxima o debate sobre a eficácia e a efetividade desses direitos, tendo em vista que não adianta que sejam positivados e reconhecidos apenas nos tribunais de justiça; tampouco é suficiente que sejam reconhecidos apenas quando violados.

Os direitos humanos, como realidade complexa capaz de garantir a todos, sem exceção, igualdade, democracia e convivência pacífica, só serão mais eficazes na medida em que haja uma sensibilidade sociocultural que permeie esses diversos espaços sociais. A positivação desses direitos fundamentais é imprescindível, mas não é o bastante. 
Os direitos humanos possuem, portanto, uma faceta de permanente dinâmica de construção espaço-temporal. Tais direitos se fazem e desfazem universais todos os dias, impedindo que sejam entendidos como estáticos, apriorísticos e prévios (RUBIO, 2010).

A dignidade humana, um dos fundamentos do Estado Democrático de Direito brasileiro, previsto no art. $1^{\circ}$, III, da Constituição Federal, é um direito humano que deve ser constantemente reinterpretado e transformado. As constantes reivindicações sociais foram gradualmente expandindo o significado do que seria vida digna universal e extensa a todos, sem qualquer exceção.

O trabalho escravo, a violência contra a mulher em suas inúmeras formas e a violência física e moral contra a diversidade sexual são exemplos de lutas sociais ainda presentes na sociedade atual que servem para exemplificar o abismo entre a positivação da norma constitucional e a realidade político-social concreta. São lutas sociais que, apesar de decorrerem de décadas, ainda dependem de um incremento de sensibilidade cultural nos mais diversos espaços sociais, pois ainda sofrem severas violações.

O Estado brasileiro possui normas que tutelam a dignidade humana. Em verdade, a dignidade é erigida como um direito fundamental que norteia a integração, interpretação e aplicação de todo o ordenamento nacional. Miranda (2007) defende que o principio da dignidade humana, no âmbito da Constituição, confere uma unidade de sentido, valor e concordância prática ao sistema dos direitos fundamentais. Todos os demais direitos fundamentais estão ancorados nesse princípio.

\section{Finalidade da pena}

O papel do Estado, ao longo da história, foi gradualmente sendo modificado e passou a assumir certos deveres perante aqueles que estavam sob sua tutela. As teorias contratualistas, que surgiram a partir do século $\mathrm{XVI}$, durante o período absolutista, defendiam que o Estado 
deveria garantir a segurança dos súditos e estes, em troca, teriam algumas de suas liberdades restringidas.

O Estado, frente às aspirações da sociedade por segurança, assume o jus puniendi, a fim de garantir um convívio social harmônico e evitar que a liberdade de um indivíduo causasse danos à liberdade de outro. O jus puniendi também deve ser construído e aplicado levando em consideração esses princípios fundamentais vigentes na Constituição e nos tratados internacionais.

No início, o Estado punia os infratores com castigos corporais, morte e banimento. Nas sociedades antigas, já politicamente organizadas, o direito de punir estava vinculado principalmente à religião e à moral. $\mathrm{O}$ medo não era produzido pelo criminoso, mas pela divindade; o crime não era um mal causado à sociedade, mas aos deuses. O julgamento moral era imposto de fora, pela ameaça divina. O direito penal antigo, o direito babilônico, hebraico, romano e medieval estavam todos permeados por uma ética religiosa. Os princípios éticos e jurídicos permaneceram ligados por muito tempo, pois o crime era tratado ao lado do pecado; e a pena, ao lado da penitência (VERGARA, 1980).

Durante os séculos XVII e XVIII, os suplícios - cerimônias punitivas aterrorizantes pautadas na crueldade e na ostentação da violência corporal contra os criminosos - serviam muito mais como forma de demonstrar o controle e a força do rei soberano.

As penas privativas de liberdade e direitos aparecem de forma mais pontual em meados do século XVIII, com as disposições de princípios decorrentes da Revolução Francesa (1789) e com a ideologia após a Segunda Guerra Mundial, em defesa das liberdades públicas e dos direitos humanos fundamentais (DOTTI, 1998).

As penas, antes instrumentos de castigo, vingança e repressão negativa do Estado, passam a se afastar das penas e torturas cruéis, desumanas, que desrespeitassem a integridade física e moral. As sanções adquirem um caráter humanitário que busca, mais do que a repressão, a reintegração, a ressocialização e a reeducação do indivíduo. 
Inseridos no âmbito do Direito Penal, tendo por base o Estado Democrático de Direito, os direitos fundamentais fixam os limites, os fins e a própria atuação funcional da tutela penal. A intervenção penal, dentro do Estado Democrático de Direito, afasta-se de uma conduta autoritária, supressora de direitos e garantias, típica dos antigos regimes, para adotar fundamentações jurídicas baseadas em princípios validados pelo ordenamento nacional e internacional.

O papel e as funções do Estado, por meio das lutas sociais ocorridas ao longo de todo o processo histórico, sofreram modificações. Cabe hoje ao Estado Democrático de Direito a busca por uma democracia participativa, pela efetivação da igualdade material, pela inclusão social, cultural e econômica, pela segurança e pelos direitos humanos. O Direito Penal, nessa conjectura, passa a ser limitado pelos valores do Estado, sendo aplicado em consonância com os direitos teorizados.

A execução da pena de prisão passa a ser condicionada por uma série de princípios que limitam o sistema penal. Surge a necessidade de concretizar a aplicação de princípios referentes à legalidade, à humanidade, à individualidade e à proporcionalidade da pena. A dignidade humana é inerente a todos os seres humanos, mesmo àqueles que violaram uma proibição legal e devem, portanto, receber uma sanção.

Os fins da pena dependem de decisões político-criminais que refletem um anseio consensual da sociedade. O Estado impõe uma privação de direitos àqueles que ferem bens jurídicos fundamentais, não só como forma de reprovar a conduta executada, mas também de prevenir novos delitos. É preciso destacar que, independentemente da finalidade que adote - ressocialização, prevenção, reintegração ou reeducação -, a pena não poderá desrespeitar o princípio da dignidade humana e seus corolários. A pena capital, nesse contexto, perde suas justificativas.

A pena de morte, para alguns, como Emílio Silva de Castro (1986) e David Nunes (1956), encontra sua legitimidade e conveniência na superioridade do bem comum e da segurança social em relação ao 
indivíduo. Nuñez (1956, p. 24) compara a pena de morte à gangrena de um paciente, pois enquanto o médico, visando ao bem de todo o corpo do paciente, corta a parte gangrenosa, a autoridade "[...] con toda justicia y suma utilidad arranca de la sociedad a los perturbadores de la paz común".

Além disso, soma-se a esse argumento a incapacidade do atual sistema penitenciário de controlar o crescimento dos índices de criminalidade por meio de suas prerrogativas de ressocialização, reeducação e repressão. Todavia, frente ao Estado Democrático de Direito e suas garantias à vida humana, a pena de morte, mesmo como exceção para tempos de guerra, perde sua força e razão.

Beccaria (2008) afirma que a morte de um cidadão seria justificável apenas em dois momentos: quando a desordem e o caos substituem as leis e a nação está prestes a perder sua liberdade; e quando o cidadão pode atentar contra a segurança pública, sendo possível acarretar em uma verdadeira revolução no governo estabelecido. Entretanto, reconhece que a pena de morte gera para a sociedade e para o criminoso um mero abalo violento e passageiro, enquanto as penas de privação de liberdade têm um poder maior de incutir temor ao criminoso.

Uma das principais justificativas para a manutenção da pena de morte em caso de guerra está centrada na importância da tarefa executada pelos soldados. Nos termos do Código Penal Militar Brasileiro, nos artigos 55 e 56, uma das penas principais é a pena de morte, que deve ser executada por fuzilamento.

A lei penal militar visa proteger o interesse do Estado e das instituições militares, que se sobrepõe a interesses entre particulares. Além disso, como destaca Nuñez (1956) se a autoridade pública pode exigir o sacrifício de um pelo bem de toda a sociedade, essa mesma autoridade tem o poder coercitivo de sancionar com a pena capital aqueles que não cumprem seu dever.

Um dos principais argumentos para a manutenção da pena de morte em tempo de guerra, feito por Mourullo (1995), é que, nesse 
contexto, há a rápida e cruel ruptura do próprio Direito, sendo necessária a repressão com pena capital aos soldados que não cumprirem seus deveres, por haver risco à vida de muitos inocentes.

Mir Puig (1995, p. 58), de forma diferente, entende que "[...] una cosa es que el Estado lleve a sus hombres a acciones militares arriesgadas, lícitas si son necesarias para la defensa, y otra, muy distinta, que él mismo prive fríamente la vida de sus ciudadanos".

\section{A incompatibilidade da pena de morte em tempo de guerra}

A humanização do Direito Penal e os valores que erigem o Estado de Direito brasileiro caminham rumo ao entendimento de Mir Puig (1995). Os princípios fundamentais de Direito Penal, tendo em vista o próprio ordenamento constitucional, devem ser postos em prática também em tempos de guerra.

É incoerente buscar instaurar a paz (objetivo finalístico da guerra) aplicando a pena de morte. A dignidade da pessoa humana é inviolável e não há espaço para relativização desse princípio. A proteção da dignidade humana é pressuposto da participação social do indivíduo no Estado democrático e condição para a efetivação de sua cidadania.

Dessa forma, a incompatibilidade da exceção constitucional se mostra no desencontro entre essa norma e as garantias fundamentais de direito à vida, à integridade física, à liberdade e demais corolários constitucionalmente defendidos e assegurados pelo Estado Democrático de Direito contemporâneo.

As fontes dessa incompatibilidade estão centradas nas bases do Estado Democrático de Direito brasileiro e de suas garantias fundamentais, tendo em vista também os princípios e normas de direitos humanos internacionais vigentes na atualidade.

Bachof (1951) analisa a existência de normas constitucionais inconstitucionais, uma vez que são conflitantes entre si. Apesar de o Poder Constituinte Originário ser incondicionado, há determinadas 
matérias de um mínimo ético que, ao serem afrontadas, culminariam na inconstitucionalidade dessa norma.

A tese de Bachoff (1951), além de polêmica, foi muito criticada, principalmente pela corrente que defende que a vontade do Poder Constituinte Originário é una e coerente e que todas as antinomias aparentes podem e devem ser eliminadas por critérios de especialidade ou por meio do sopesamento de princípios.

Sem analisar o mérito da tese jurídica do professor alemão, mas lançada a ideia de que há um mínimo ético a ser garantido mesmo pelo Poder Constituinte Originário, e pautando-se, ainda, na ideia de direitos humanos como uma estrutura mais complexa que se constrói dinamicamente e depende de uma sensibilidade sociocultural desses direitos que atinja todos os espaços sociais, resta a questão sobre como compatibilizar a pena de morte em tempo de guerra, permitida constitucionalmente no Brasil, com todas as recentes conquistas em relação aos direitos humanos. Além disso, cumpre questionar qual o valor e o significado da manutenção dessa previsão legal.

Os crimes previstos no Código Penal Militar punidos com pena de morte, executada por fuzilamento, são: de favorecimento pessoal (art. 350, Código Penal Militar), traição (art. 355, Código Penal Militar), favor ao inimigo (art. 356, CPM), tentativa contra a soberania do Brasil (art. 357, CPM), coação a comandante (art. 358, CPM), informação ou auxílio ao inimigo (art. 359, CPM), aliciação de militar (art. 360, CPM), ato prejudicial à eficiência da tropa (art. 361, CPM), traição imprópria (art. 362, CPM), cobardia qualificada (art. 364, CPM), fuga em presença do inimigo (art. 365, CPM), espionagem (art. 366, CPM), motim, revolta ou conspiração (art. 368, Parágrafo único, CPM), incitamento em presença do inimigo (art. 371, CPM), rendição ou capitulação (art. 372, CPM), falta de cumprimento de ordem (art. 375, Parágrafo único, CPM), separação reprovável (art. 378, CPM), abandono de comboio (art. 379, 1, CPM), dano especial (art. 383, CPM), dano em bens de interesse militar (art. 384, CPM), envenenamento, corrupção ou epidemia (art. 385, CPM), crimes de perigo comum (art. 386, II, CPM), recusa de obediência 
ou oposição (art. 387, CPM), violência contra superior ou militar de serviço (art. 389, CPM), abandono de posto (art. 390, CPM), deserção em presença do inimigo (art. 392, CPM), libertação de prisioneiro (art. 394, CPM), evasão de prisioneiro (art. 395, CPM), amotinamento de prisioneiros (art. 396, CPM), homicídio qualificado (art. 400, III, CPM), genocídio (art. 401, CPM), lesão corporal grave (art. 403, §3 ${ }^{\circ}, \mathrm{CPM}$ ), roubo ou extorsão (art. 405, CPM), saque (art. 406, CPM), violação carnal (art. 408, Parágrafo único, alínea b), CPM).

A justificativa de Beccaria (2000) de que a pena de morte só seria aceitável quando a ordem do Estado fosse substituída pelo caos, assim como os argumentos de Mourullo (1995) de que em situação de guerra haveria um bem maior a ser tutelado (a vida de todos os cidadãos) perdem força quando se parte do pressuposto de que os direitos humanos são uma realidade complexa, pois vão além da mera positivação das leis e devem ser incutidos nas relações humanas em seus mais diversos espaços. Ressaltando-se que devem ser direitos de todos, sem qualquer exceção.

As justificativas perdem força porque tais pressupostos impedem qualquer tipo de relativização. Os direitos humanos, em especial o princípio da dignidade humana, devem ser respeitados e tutelados em qualquer circunstância que o Estado se encontre.

A ressalva constitucional de exceção à pena de morte para crimes militares, diante de todo o arcabouço de direitos humanos paulatinamente construído e defendido pelo Estado brasileiro, mostra-se ilegítima. Não há justificativas que possam relativizar a dignidade humana.

Analisando o tratamento da pena de morte em outros países, para parâmetro de comparação com a situação atual, mas sem se enveredar para o eurocentrismo ibero-americano de formação da cultura jurídica hegemônica, é paradigmática a situação de Portugal, que na década de 1960 realizou, na Universidade de Coimbra, de 11 a 16 de setembro de 1967, o Colóquio Internacional Comemorativo do Centenário da Abolição da Pena de Morte em Portugal. Na Espanha, houve avanços e retrocessos ao longo de sua história, sendo impostas 2.078 penas de 
mortes entre 1870 e 1961, até a sua abolição pela Constituição de 1978, para os períodos de paz.

A Organização das Nações Unidas (ONU) conta com 193 paísesmembros; desses, 140 já aboliram ou não aplicam a pena de morte. Em 1977, a Anistia Internacional começou a trabalhar para acabar com a pena de morte. Ainda hoje, luta para que todos os Estados terminem com essa punição cruel, desumana e degradante. Em 1984, após pressão exercida pela Anistia Internacional, as Nações Unidas adotaram a Convenção contra a Tortura.

Em 2007, a Assembleia Geral da ONU aprovou, por 104 votos a favor, 54 contra e 29 abstenções, uma moratória da pena de morte. A moratória corresponde à suspensão geral, e não à abolição, da pena de morte em todo o mundo. Ela determina aos Estados-membros da ONU, que ainda possuam pena de morte, que eles gradativamente rumem à abolição e, ao mesmo tempo, restrinjam o número de delitos para os quais é utilizada.

Ademais, a moratória tenta coibir que os Estados que já aboliram a pena não a reintroduzam em seu ordenamento. Entretanto, por ser uma diretriz resultante de uma resolução da Assembleia Geral, não tem efeito vinculante para os Estados-membros da ONU, ou seja, os países que atualmente tem a pena de morte não são forçados pela legislação internacional a pararem de executar os condenados.

Segundo dados da Anistia Internacional (2012), de 198 países do mundo, apenas 20 realizaram execuções no ano de 2011. Em 2002, eram 31 os países que puniam com pena capital. Há, como se pode observar, um avanço, todavia, a Anistia considera preocupante a quantidade de execuções em países como China, Arábia Saudita, Irã, Iraque e Estados Unidos.

\section{Conclusão}

O Supremo Tribunal Federal já declarou no ADIN 815-3/96 que a tese de que há hierarquia entre normas constitucionais originárias dando azo à declaração de inconstitucionalidade de umas em face de 
outras é incompossível com o sistema de Constituição rígida. Miranda (1983) afirma que pode haver inconstitucionalidade entre normas constitucionais preexistentes e supervenientes, mas tal oposição não é possível quando se trata de inconstitucionalidade entre normas feitas ao mesmo tempo e por uma mesma autoridade jurídica.

O STF defende que, nesses casos, não haveria problema de inconstitucionalidade, mas uma questão de ilegitimidade:

[...] não cremos que, a dar-se qualquer forma da contradição ou de violação dessa axiologia, estejamos diante de uma questão de inconstitucionalidade, mas sim diante de uma questão que a ultrapassa [...]. No extremo, poderá haver invalidade ou ilegitimidade da Constituição. (MIRANDA, p. 290).

A tese de Bachof (1951) de que há normas constitucionais inconstitucionais, mesmo quando elas derivam do constituinte originário, por estar esse Poder subordinado a um direito suprapositivo, embora já tenha sido afastada, serve como ponto de partida para nova reflexão.

Os direitos humanos, entendidos a partir do modelo proposto por Rubio (2010), de uma perspectiva emancipadora e que busca uma construção dinâmica, conflitiva e constante da universalidade desses direitos, mostra que a exceção constitucional e a norma infraconstitucional do Código Penal Militar, que prevê a pena capital por fuzilamento para diversos crimes militares, mostram-se em desencontro com as garantias fundamentais.

As fontes dessa incompatibilidade estão centradas nas bases do Estado Democrático de Direito brasileiro, tendo em vista também os princípios e normas dos direitos humanos internacionais vigentes na atualidade. O princípio da dignidade da vida humana, ponto de partida para a construção e aplicação de todo o ordenamento jurídico brasileiro, não permite que a morte aplicada pelo Estado seja legitimada.

É incoerente buscar instaurar a paz (objetivo finalístico da guerra) aplicando a pena de morte. A dignidade da pessoa humana é inviolável e não há espaço para a relativização desse princípio. 


\section{Referências}

ALEXY, Robert. Teoria dos direitos fundamentais. Tradução Virgílio Afonso da Silva. São Paulo: Malheiros, 2008.

AMNESTY INTERNACIONAL. Deathsentencesandexecutions in 2011. Disponível em:<http://www.amnesty.org/en/death-penalty/deathsentences-and-executions-in-2011>. Acesso em: 22 ago. 2014.

BACHOF, Otto. Normas constitucionais inconstitucionais? Coimbra: Atlântida, 1951.

BECCARIA, Cesare. Dos delitos e das penas. Tradução de Torrieri Guimarães. São Paulo: Martin Claret, 2008.

BOBBIO, Norberto. A era dos direitos. Rio de Janeiro: Campus, 1992. BORGES, Paulo César Corrêa. Direito penal democrático. Franca: Lemos \& Cruz, 2005.

A tutela penal dos direitos humanos. Disponível em: <http:// www.perio dicos.uem.br/ojs/index.php/EspacoAcademico/article/ view/15059/9457>Acesso em: 22 ago. 2014.

COLÓQUIO INTERNACIONAL COMEMORATIVO DO CENTENÁRIO DAABOLIÇÃO DE PENA DE MORTE EM PORTUGAL. Pena de morte: comunicações. Coimbra: Faculdades de Direito de Universidade de Coimbra, 1967. 2v.

DOTTI, René Ariel. Bases alternativas para o sistema de penas. 2. ed. São Paulo: Revista dos Tribunais, 1998.

ESPAÑA. Constituicion Española. Boletin Oficial del Estado Gaceta de Madrid, Madrid, v. 318, n. 311.1, 29 dec. 1978. Disponível em: <http:// www.boe.es/boe/dias/1978/12/29/pdfs/A29313-29424.pdf >.Acesso em: 22 ago. 2014.

FOUCAULT, Michel. Vigiar e punir: nascimento da prisão. Petrópolis: Vozes, 1987.

LOUREIRO NETO, José da Silva. Direito penal militar. 4. ed. São Paulo: Atlas, 2001. 
MIR PUIG, Santiago. Función de la pena y teoria del delito enel Estado social y democrático de derecho. 2. ed. rev. Barcelona: Bosch, 1982. Disponível em: <pt.scribd.com/doc/30823645/Mir-PuigFuncion-de-la-Pena-y-Teoria-del-delito>. Acesso em: 12 jul. 2014.

MIRANDA, Jorge. Teoria do Estado e da constituição. Rio de Janeiro: Forense, 2007.

. Manual de direito constitucional. 2. ed. Coimbra: Editora Coimbra, 1983. t.II.

PÉREZ, Carlos Martínez-Buján. La pena de muerte en tiempos de guerra: una abolición necesaria. In: AMNISTIA INTERNACIONAL (Ed.). La pena de muerte y su abolicion en España. Madrid: Los Librosde la Catarata, 1995. Disponível em: <http://books.google.com.br/books?id =Z2pZl2kkaSAC\&printsec=frontcover \&hl=pt-BR\&source=gbs_ge_sum mary_r\&cad=0\#v=onepage\&q\&f=false> .Acesso em: 22 ago. 2014 .

NUÑEZ, David. La pena de muerte: frente a la iglesia y al Estado. Buenos Aires: [s.n.], 1956.

ORGANIZAÇÃO DAS NAÇÕES UNIDAS. Declaração Universal dos Direitos Humanos.1948. Disponível em: <http://unicrio.org.br/img/ DeclU_D_HumanosVersolnternet.pdf>. Acesso em: 22 ago. 2014.

. Pacto de São José da Costa Rica. 1969. Disponível em: <www.pge.sp.gov.br/centrodeestudos/bibliotecavirtual/instrumentos/ sanjose.htm>.Acesso em: 22 ago. 2014.

PÉREZ, Carlos Martínez-Buján. La pena de muerte en tiempos de guerra: una abolición necesaria. In: AMNISTIA INTERNACIONAL (Ed.) La pena de muerte y su abolicion en España. Madrid: Los Libros de la Catarata, 1995. Disponível em: <http://www.books.google.com/book $\mathrm{s}$ ?id=Z2pZl2kkaSAC\&printsec=frontcover\&hl=pt-BR\&source= gbs_ge summary_r\&cad=0\#v=onepage\&q\&f=false>Acesso em: 22 ago. 2014 .

PIOVESAN, Flávia. Direitos humanos e o direito constitucional internacional. 11. ed. rev. e atual. São Paulo: Saraiva, 2010.

SILVA, José Afonso da. Curso de direito constitucional positivo. 33. ed. São Paulo: Malheiros, 2009. 


\section{ANEXO}

PENA DE MORTE

\begin{tabular}{|c|c|c|}
\hline & $\begin{array}{l}\text { QUANTIDADE } \\
\text { DE PAÍSES }\end{array}$ & ROL EXEMPLIFICATIVO \\
\hline $\begin{array}{l}\text { ABOLIDA PARA } \\
\text { TODOS OS TIPOS } \\
\text { DE CRIMES }\end{array}$ & 97 & $\begin{array}{l}\text { Angola, Argentina, Austrália, Áustria, } \\
\text { Azerbaijão, Canadá, Colômbia, Costa } \\
\text { Rica, Equador, França, México, Portugal, } \\
\text { Romênia, Ruanda, África do Sul, Espanha, } \\
\text { Timor-Leste, Turquia, Venezuela }\end{array}$ \\
\hline $\begin{array}{l}\text { ABOLIDA PARA } \\
\text { CRIMES } \\
\text { COMUNS }\end{array}$ & 8 & $\begin{array}{l}\text { Bolívia, Brasil, Chile, El Salvador, Fiji, } \\
\text { Israel, Cazaquistão, Peru }\end{array}$ \\
\hline $\begin{array}{l}\text { ABOLIDA NA } \\
\text { PRÁTICA }\end{array}$ & 35 & $\begin{array}{l}\text { República do Congo, Laos, Madagascar, } \\
\text { Marrocos, Serra Leoa, Coreia do Sul, } \\
\text { Sri Lanka, Suriname, Tanzânia, Tonga, } \\
\text { Tunísia, Zâmbia }\end{array}$ \\
\hline AINDA VIGENTE & 58 & $\begin{array}{l}\text { Afeganistão, Arábia Saudita, Bahamas, } \\
\text { Bahrain, Bangladesh, Barbados, } \\
\text { Belarus, Belize, Bielorrússia, República } \\
\text { Democrática do Congo, Cuba, Egito, } \\
\text { Etiópia, Guatemala, Índia, Indonésia, Iran, } \\
\text { Iraque, Jamaica, Japão, Líbano, Líbia, } \\
\text { Malásia, Nigéria, Coreia do Norte, Omã, } \\
\text { Paquistão Qatar, Singapura, Somália, } \\
\text { Sudão, Sudão do Sul, Síria, Tailândia, } \\
\text { Trinidad e Tobago, Uganda, Emirados } \\
\text { Árabes, Estados Unidos, lêmen, Zimbábue }\end{array}$ \\
\hline
\end{tabular}

Recebido em: 26/09/13

Aprovado em: 04/09/14 